\title{
POESÍA E HISTORIA EN EL COMPENDIO HISTORIAL (1630) DE MELCHOR JUFRÉ DE ÁGUILA ${ }^{1}$
}

\author{
Julio Sebastián Figueroa \\ University of Pennsylvania \\ juliof@sas.upenn.edu
}

RESUMEN / ABSTRACT

En este artículo analizo el cruce entre poesía e historia en el Compendio Historial del Descubrimiento y Conquista del Reino de Chile (1630) de Melchor Jufré de Águila. Para este fin, describo primero la trayectoria material del libro con el propósito de distinguir prácticas de escritura y publicación asociadas a determinados órdenes del discurso. Enseguida, discuto los diferentes modelos historiográficos y poéticos que atraviesan el texto, considerando la tradición humanista de la crónica abreviada y la sustitución de la épica por la poesía gongorista como modelo de representación de la conquista a principios del siglo XVII. Finalmente, analizo la crítica de Jufré de Águila a la guerra defensiva, así como la controversia que mantuvo con el misionero jesuita Luis de Valdivia, para demostrar uno de los conflictos discursivos que se sostuvieron en el naciente orden letrado del Chile colonial.

Palabras clave: Melchor Jufré de Águila, Chile del siglo XVII, compendio histórico, poética, Luis de Valdivia.

In this article, I analyze the intersections between poetry and history in Melchor Jufré de Águila's Compendio Historial del Descubrimiento y Conquista del Reino de Chile (1630). To that end, I first describe the book's material trajectory in order to distinguish writing and publishing practices linked to specific orders of the discourse. Then I discuss the different historiographic and poetic models used in the text, examining the humanist tradition of the abbreviated chronicle and the substitution of the epic poetry by Gongorist poetry as the model

1 Agradezco profundamente a Roger Chartier y Jorge Téllez por sus valiosos comentarios y rigurosa lectura del texto. Asimismo, agradezco a los lectores anónimos proporcionados por la revista por sus generosas y atingentes observaciones. 
for representing the conquest at the beginning of the seventeenth century. Finally, I analyze Jufré de Águila's critique of defensive war, as well as his dispute with Jesuit missionary Luis de Valdivia, illustrating some of the discursive conflicts that were held in the nascent lettered order of colonial Chile.

KEYWords: Melchor Jufré de Águila, seventeenth-century Chile, poetics, Gongorism, Luis de Valdivia.

\section{INTRODUCCIÓN}

Melchor Jufré de Águila, capitán de la corona española en la Guerra de Arauco y alcalde ordinario de Santiago en los inicios del siglo XVII, escribió en 1614 un memorial dirigido al Rey Felipe III, contando las difíciles condiciones que se vivían en el Reino de Chile. En su misiva aprovechó para pedir que se le autorizara a escribir una crónica de los hechos de la conquista acontecidos en esa parte del imperio, puesto que estos

estaban oscurecidos, con perpetuo olvido, a causa de no haberse mandado hacer historia a quien la escriba aquí, que en España tendrá mil defectos por la distancia grande, aunque el cronista sea más cuidadoso y diligente que los pasados, pues al fin tendrá muchos imposibles; $y$ los que algo ahora aqui y antes han escrito es todo en verso, el que es poco capaz de historia, pues uno de ellos hizo un gran libro de lo que en historia en dos o tres capitulos se pudiera decir mejor y con más verdad. Para remedio de lo cual, suplico a V.M. (...) se sirva dignarse de mandarse informar de quien en este reino tenga suficiencia para hacer esta historia, y mandarle nombrar por su cronista de él, que aunque sea con poco salario (...) que de mi digo que si me cupiese tan dichosa suerte (...) me tendría por bien premiado de mis servicios, de que hasta ahora no lo estoy (...) (cit. en Medina 1897: 365; bastardillas mías).

Aunque no hay registro de la respuesta entregada por el Consejo del Rey a la petición de Jufré de Águila, tampoco hay evidencia de que este haya sido nombrado cronista oficial del Reino de Chile. Así, podemos sostener que la petición fue denegada, especialmente si consideramos que, a medida que la conquista de América se hacía más extensa y compleja, la regulación de narrativas sobre las nuevas posesiones de la corona se hacía también cada día más estricta, privilegiándose los informes a pedido así como la labor 
del Cronista Mayor de Indias por encima de las cartas y relaciones libres de conquistadores.

La publicación en 1630 del Compendio Historial del Descubrimiento y Conquista del Reino de Chile, una crónica de la conquista de Chile firmada por Jufré de Águila, indica que este perseveró en su proyecto escriturario pese a la indiferencia del Consejo. Este gesto no era infrecuente en los territorios coloniales y menos en Chile, en que relaciones de hechos y cosas sobre esta región circularon profusamente después de la publicación de la primera parte de La Araucana (1569). Los poemas épicos Arauco domado de Pedro de Oña (1596) y Purén indómito de Diego Arias de Saavedra (1599); así como las relaciones históricas Crónica del Reino de Chile de Pedro Mariño de Lobera (1598) e Histórica relación del Reino de Chile de Alonso de Ovalle (1647) se cuentan entre los ejemplos más conocidos. Lo que llama la atención, sin embargo, es que Jufré de Águila haya concebido su obra sin echar mano de los recursos en prosa que ofrecía la crónica, sino que en forma de diálogo poético, es decir, en esa forma 'poco capaz de historia', como él mismo había sostenido en su memorial, que es el verso.

Mi intención es discutir la propuesta escritural de Jufré de Águila materializada en el Compendio Historial a través de la poética de la historia en que se funda. Para este propósito describo, primero, la trayectoria material del libro desde su publicación hasta su recensión por la crítica decimonónica chilena. Enseguida, discuto los géneros discursivos en que se inscribe, poniendo énfasis en la relación de la obra con La Araucana y otras poéticas difundidas por el territorio americano. Finalmente, analizo la crítica que se realiza en el Compendio Historial a la estrategia defensiva propugnada por Luis de Valdivia en la Guerra de Arauco, ilustrando con ello las posiciones en juego dentro de un orden letrado que comienza a entenderse localmente.

\section{TRAYECTORIA MATERIAL}

Considero que el Compendio Historial de Jufré de Águila ofrece un interesante caso de análisis de las prácticas escriturales que se desarrollaban en Chile a principios del siglo XVII. Para entender a cabalidad estas prácticas, es necesario revisar su trayectoria material como libro. De acuerdo con Roger Chartier (1992), los libros "son des objets dont les formes commandent, sinon l'imposition du sens des textes qu'ils portent, du moins les usages qui peuvent les investir et les appropriations dont ils sont susceptibles. Les 
œuvres, les discours n'existent qu'à partir du moment où ils deviennent des réalités physiques" $(8)^{2}$. Así, estudiar la trayectoria material de una obra implica estudiar su circulación como objeto de cultura, reconociendo sus características formales, editoriales e institucionales, entre otras, desde un punto de vista histórico. Esto permite abordar con más profundidad aquellos órdenes del discurso en que se inscriben los textos. Entiendo por orden del discurso la manera en que, de acuerdo con Michel Foucault (1970; 2005), "la producción del discurso está a la vez controlada, seleccionada y redistribuida por cierto número de procedimientos que tienen por función conjurar sus poderes y peligros, dominar el acontecimiento aleatorio y esquivar su pesada y temible materialidad" (14). Como ha afirmado en otro ensayo R. Chartier (2014), todo orden del discurso es siempre también un orden de libros, es decir, "an order of the written word closely associating the authority of knowledge and the form of publication" (6) ${ }^{3}$. Por lo tanto, lo que me interesa es trazar brevemente la trayectoria material del Compendio Historial con el fin de distinguir prácticas concretas de producción y recepción y, en consecuencia, órdenes del discurso y del libro asociados a él.

El texto de Jufré de Águila fue publicado originalmente en 1630 en una edición que contenía el poema titulado Compendio Historial del Descubrimiento, Conquista y Guerra de Chile, continuada por término de casi noventa años, hasta el mil y seiscientos y veintiocho; así como dos "discursos a él conjuntos" también escritos en verso: Avisos Prudenciales en las Materias de Gobierno y Guerra; y De lo que Católicamente se debe sentir de la Astrología Judiciaria. Impreso en Lima por Francisco Gómez Pastrana y dedicado al Conde de Chinchón, entonces Virrey del Perú, presenta una licencia otorgada por Jusepe de Cáceres, secretario de la gobernación de Lima, en la que se fija la tasa del libro en un real por cada pliego y se concede privilegios de manera exclusiva sobre el libro al autor.

En cuanto a este último, Jusepe Cáceres lo describe en su licencia como "vecino encomendero de la ciudad de Santiago, cabeza de la gobernación

\footnotetext{
"son objetos cuyas formas, si no pueden imponer el sentido de los textos que contienen, al menos determinan los usos que pueden asignárseles y las apropiaciones de las que son susceptibles. Las obras, los discursos no existen sino desde el momento en que devienen realidades físicas" (traducción mía). Existe traducción al español en Roger Chartier, El orden de los libros, Barcelona, Gedisa, 1994, a la cual, sin embargo, no tuve acceso.

"un orden de la palabra escrita que asocia íntimamente la autoridad del conocimiento a la forma de publicación" (traducción mía).
} 
de Chile, cabo y capitán a guerra della" (Compendio 3$)^{4}$. La Biblioteca Hispano-Chilena de José Toribio Medina (1897), que incluye una completa biografía del autor gracias a memoriales y documentos administrativos emitidos durante sus periodos como alcalde, señala que Jufré de Águila había salido de Madrid como jefe de lanza en dirección al Perú en 1588 para luego encaminarse en 1590 por sus propios medios hacia Chile como apoyo a las misiones de Alonso García de Ramón. Herido en la segunda de sus campañas en territorio mapuche, perdió su hacienda y fue "vejado y molestado de muchos acreedores que tiene" (320). En 1600 se le concedió sobrecédula de jefe de lanza para vivir en el Reino de Chile, retribuyéndosele los empréstitos realizados al gobierno por su primera esposa, Doña Beatriz Guzmán (338). Asentado en calidad de encomendero, participó vivamente del gobierno colonial en la ciudad de Santiago hasta su retiro en los extramuros de la misma, dedicando sus últimos años al campo y a la actividad literaria (367). El testamento que dejó tras su muerte en 1636, copiado íntegramente por Medina, indica que su obra no se limitó al Compendio Historial, sino que esta sería parte de una obra de tres tomos intitulada Coloquio sentencioso de provecho y gusto. Otro "pequeño volumen" consignado en el testamento, de título Cotejo racional, al parecer no llegó a publicarse (343). Luis Merlo de la Fuente, en la carta incluida en la edición original del libro de 1630, menciona también una Historia general de la conquista y guerra del Reino de Chile, de la que el Compendio Historial habría sido un resumen (Compendio 43); sin embargo, parece que esta Historia no fue terminada o nunca se publicó. En conclusión, la edición de Lima de 1630 sería el único vestigio de la obra de Jufré de Águila ${ }^{5}$ de que disponemos.

\footnotetext{
4 A lo largo de todo el artículo, citaré de la edición de la Universidad de Chile hecha en 1897.

Cabe destacar el interés del autor por la biblioteca consignada en su testamento, la cual habría consistido en 80 libros (Medina 367). El cuidadoso tratamiento que demanda sobre estos ejemplares, entendidos como propiedad y objetos de valor, grafica la íntima conexión entre orden letrado y orden económico. Por su parte, la incansable preocupación por créditos, préstamos y deudas que evidencian los documentos personales de Jufré de Águila permiten hacernos una idea acerca del lugar de un conquistador de mediana importancia en la estructura social de la colonia, así como del carácter semi privado de la empresa de conquista. Los estudios de Juan G. Muñoz Correa (2006 y 2008) sobre concesiones territoriales en Santiago y alrededores durante los siglos XVI y XVII, en los que Jufré de Águila aparece como beneficiario, revela asimismo el rol que tuvieron los encomenderos en el proceso de asentamiento del imperio español en las nuevas posesiones territoriales.
} 
El libro pasó prácticamente inadvertido en la biblioteca colonial hasta que en 1897, más de dos siglos después de su primera impresión, fue reeditado por la Universidad de Chile. Diego Barros Arana, en su introducción a esta reedición, afirma que por mucho tiempo el Compendio Historial constituyó una "peregrina curiosidad" equívocamente mencionada en algunas bibliografías del siglo XVIII y especula sobre el interés que pudieron tener los seguidores del jesuita Luis de Valdivia en hacerlo desaparecer, aunque sobre esta hipótesis no existe evidencia (ver "Don Melchor Jufré de Águila y su libro" I, X). Solo el bibliógrafo español Pascual de Gayangos (1856), en las notas bibliográficas que añadió a la traducción que hiciera junto a Enrique de Vedia del libro de George Ticknor History of Spanish Literature (1849), había dado pruebas de haber visto físicamente el texto, describiéndole entonces como un "poema macarrónico" de tan malos versos "que no nos acordamos de haberlos leído peores ni mas prosaicos" (“Adiciones y notas" 472).

Gayangos había vendido su ejemplar del libro al estadounidense John Carter Brown, hijo del fundador de Brown University, en cuya biblioteca se resguarda hasta el día de hoy, sin que haya noticia de otro ejemplar. En 1895, por intermedio de la Embajada de Chile en Washington, la Universidad de Chile encargó una copia manuscrita del Compendio Historial que reprodujo al año siguiente como parte de sus anales, incluyendo la introducción de Barros Arana así como una advertencia de Luis Montt, mas no los dos discursos que acompañaban la edición original. Poco después, la misma universidad publicó la versión completa del Compendio Historial, incluyendo un apéndice con documentos personales del autor, entre ellos su testamento. Para la redacción de este artículo, consulté esta edición y la versión digital que hiciera la Universidad de Chile en su sitio web sobre fuentes documentales de la historia de Chile. La copia digital hecha por Brown University a partir de la edición de 1630 también fue consultada (ver Jufré de Águila 1630 y 1897). Hay que consignar que el sitio web Memoria chilena de la Biblioteca Nacional de Chile, en el que se puede encontrar referencia de prácticamente toda la producción textual de la colonia, no hace ninguna referencia al Compendio Historial y apenas nombra a su autor en el contexto de una cápsula biográfica sobre Ginés de Lillo, visitador de tierras entre 1602-1605, a quien Jufré de Águila habría precedido en el cargo.

Cabe señalar que el Compendio Historial significó a los ojos de Barros Arana una mala copia de La Araucana, un poema de "escaso valor histórico" y "fatigosa lectura" (viii). Más aún, puso en duda si se le podía llamar poema y describió sus versos como "laboriosamente medidos, aunque faltos de armonía 
i de regularidad métrica, i desprovistos de todo colorido poético" (ix). Si bien es cierto que la obra es desigual y fatigosa, creo que Barros Arana se equivoca al valorarla de acuerdo al modelo de La Araucana, considerada por la crítica decimonónica chilena origen de la literatura nacional y vara para medir todas las demás obras poéticas del periodo. Para Jufré de Águila, así como para muchos letrados de entonces, el poema de Ercilla era una obra excepcional que, sin embargo, cuestionaba el proyecto de expansión imperial que llevaban a cabo los conquistadores día a día. Por esa razón, muchos de ellos miraron ese modelo desde una posición crítica. Mi propuesta, en este sentido, es leer el Compendio Historial en su singularidad, es decir, como un texto que no responde al canon de la crónica de Indias ni al de la poesía épica del Siglo de Oro, sino que adapta ideas historiográficas y poéticas provenientes de diferentes tradiciones para encontrar una fórmula discursiva adecuada al contexto local.

\section{HISTORIA Y POESÍA EN EL COMPENDIO HISTORIAL}

El texto del Compendio Historial es un diálogo poético en endecasílabos dividido en siete partes en el que Provecto, veterano de la Guerra de Arauco, relata a Gustoquio, veterano de la Guerra de Flandes, los hechos principales de la conquista de Chile. Desde el punto de vista histórico, cubre los sucesos ocurridos entre la primera incursión de Almagro en territorio chileno (1535) y el gobierno de Luis Fernández de Córdoba y Arce (1625-1629), poniendo especial atención a los gobiernos de Alonso García de Ramón (1600-1601 y 1605-1610), Luis Merlo de Fuente (1610-1611) y Alonso Ribera (1601-1605 y 1612-1617). Otro foco de interés en el relato son los perjuicios acarreados por la guerra defensiva tras la muerte de Óñez de Loyola en 1598. En ese sentido, el texto completa la historia contada por Ercilla, que llega hasta 1568, y la de Pedro Mariño de Lobera, que llega hasta 1598.

El libro presenta varios preliminares: un "Prólogo al lector"; una dedicatoria al Conde de Chinchón; tres sonetos encomiásticos escritos por terceros; y una larga carta escrita por el Dr. Luis Merlo de la Fuente, gobernador de Chile entre 1610 y 1611, en la que relata sus campañas en territorio mapuche y da cuenta de los beneficios de una estrategia militar ofensiva. Aunque responden a contextos discursivos distintos, todos estos preliminares tienen por objetivo fundamental dotar a Jufré de Águila de autoridad moral para escribir el Compendio Historial. En el prólogo, por ejemplo, este enfatiza su condición de capitán de guerra y testigo de los hechos que cuenta. Enseguida, 
refiere cómo al llegar a la vejez debió dejar las armas y dedicarse al estudio de "doctos libros" y "diversa lección de santos, escrituras, políticos, filósofos, i de historia" (7). Finalmente, habiendo "gastado tres años en limarle" pudo dar fin al "poema dilatado" que constituye la obra (7-8). Una perspectiva similar encontramos en los sonetos encomiásticos y en la carta de Merlo de Fuente, en los que el autor es calificado de soldado valiente e "hidalgo bien entendido en cosas de poesía" (39). De esta forma, Jufré de Águila adquiere el respaldo necesario, por su estatus de testigo y por una trayectoria virtuosa en las armas y las letras, para escribir su historia del Reino de Chile.

La mayor parte del relato está enunciado en forma sintética y ejemplar, aunque los hechos posteriores al Desastre de Curalaba son contados un poco más en detalle y acompañados de críticas hacia la política de la Corona. La estructura está determinada por el diálogo entre los personajes, pero en gran medida puede ser definida como un soliloquio de Provecto. Si tenemos en cuenta la noción de Coloquio sentencioso, en la que Jufré de Águila agrupaba el Compendio Historial tanto en su prólogo como en su testamento, el texto tendría por objeto conciliar puntos de vista diversos sobre una materia conflictiva, en este caso, la Guerra de Arauco. Sin embargo, por sobre la estructura del diálogo prima la del compendio histórico que da título al libro. Según el diccionario de Covarrubias, compendio se define comúnmente como aquel "discurso, razonamiento, o libro, que se ha recogido y abreviado de mayor volumen, ciñéndole con lo necesario y essencial de la materia" (1611: 229, f. 2). Esta primera indicación advierte sobre la condición relacional de todo compendio, que se genera siempre a partir de otro de mayor volumen que le antecede y que puede o no subsistir. Esto es coherente con la mención que hace Merlo de la Fuente en su carta acerca de otro hipotético texto escrito por Jufré de Águila, de título Historia general, del cual el Compendio Historial sería a su vez resumen.

El género del compendio histórico se inscribe en una tradición humanista que se inicia en la Península ibérica tras el reinado de Alfonso X. Los cronicones o refundiciones de las crónicas generales de la historia de España, tan importantes en el período alfonsí, se hicieron frecuentes en la Península durante los siglos XIV y XV. Tales refundiciones se caracterizaron no solo por resumir lo que podrían contar de modo más dilatado, sino que también porque eran un resumen del mundo desde su creación hasta el momento presente. Un ejemplo temprano de este tipo de textos es la Crónica abreviada de Don Juan Manuel de 1320-1325. Otro es la Suma de las crónicas de España o epitome de su historia, compuesta por Pablo de Santa María hacia 1413, quien además escribiría otra crónica en verso titulada Siete Edades del mundo 
en 1435. Tanto la Compendiosa Historia Hispánica de Rodrigo Sánchez de Arévalo (1470), como el Compendio Historial de Diego Rodríguez de Almela (1487) contienen ya la fórmula que ocuparía Jufré de Águila en el título de su libro más de un siglo después. En el Nuevo Mundo, el adelantado Gonzalo Jiménez de Quesada escribió un Compendio Historial de las conquistas del Nuevo Reino (1572-1575), del que tenemos noticias gracias a diferentes testimonios, aunque el texto se encuentra actualmente perdido (sobre este último, ver Quesada Gómez 2007).

La tradición del compendio tenía como principal recurso retórico la brevitas. Como ha estudiado Leonardo Espitia (2014), esta figura era considerada desde la antigüedad una de las "virtudes narrativas esenciales del historiador" (102) y su utilidad podía verse sobre todo en el ámbito jurídico. Un ejemplo de esto, en el contexto americano, es la Brevísima relación de la destrucción de las Indias (1552) de Bartolomé de Las Casas, un resumen de otro texto de mayor volumen en el que venía trabajando el dominico desde mucho antes y que fue concebido para ser leído como argumento ante el rey en el marco de la controversia de Valladolid. Para Espitia, la brevitas habría permitido a los humanistas españoles del Renacimiento dar a conocer los hechos con naturalidad, sin artificios retóricos innecesarios. De ahí que Jufré de Águila estuviera interesado en producir un relato más breve y claro que las demás crónicas que circulaban por el territorio. Exhibe, en ese sentido, una preocupación muy evidente no solo por ser breve, sino también por ser rápido e incluso el primero, como lo indica en su prólogo: "he sido yo el primero que, tan falto de todos requisitos, me he estrenado en tanto atrevimiento [de escribir esta historia]" (11). Quizá por este motivo la brevitas viene acompañada en el Compendio Historial de un uso recurrente de la festinatio, figura relacionada con la velocidad en el discurso. Muchos episodios son explícitamente apurados por los interlocutores, pues Gustoquio está dispuesto a escuchar el relato si Provecto no se cansa "de aquí a las cinco y media", en cuyo caso "el tiempo y el aplauso es vuestro todo" (46). Un acontecimiento de gran importancia como el Desastre de Curalaba es, de hecho, directamente omitido por Provecto. Este suele aducir que casos como estos "son cuentos largos que más tiempo piden" (99) y que la obra "no es historial, sino compendio" (102) .

6 El autor recomienda al lector ir a su Astrología Judiciaria para conocer los detalles de esta derrota que terminó con la vida del gobernador Óñez de Loyola. Tal transposición, 
Si los modelos historiográficos del Compendio Historial pueden encontrarse en la tradición humanista española, así como en algunas relaciones históricas sobre la América colonial, los modelos poéticos que subyacen al mismo son un poco más difíciles de precisar. El hecho de que el texto esté escrito en verso no impide que su propósito sea mayormente cronístico y que lo leamos como historiografía antes que como poesía. Cabe preguntarse, sin embargo, por qué tanto Jufré de Águila como los autores de los sonetos encomiásticos de los preliminares se refieren al libro como poema. Todo indica que hay una pretensión de inscribir el Compendio Historial en las poéticas del período, pero de manera muy imprecisa o, al menos, singular. De acuerdo con Jorge Téllez (2012), los escritores de la América colonial se caracterizaron, a causa del lugar periférico desde el que hablaban, por articular ideas y tradiciones literarias muy diferentes entre sí, como podían ser las poéticas clásicas, italiana o española o los discursos emergentes en los propios territorios coloniales. Considero que esta articulación, en ocasiones tan híbrida, puede verse operando en el Compendio Historial por medio de tres modelos poéticos que atraviesan el texto: la poética horaciana, el barroco y la épica. Estos modelos, no obstante, no definen el texto y aparecen solo parcialmente. Tal es el caso del barroco, que se ve reducido a sus manifestaciones más instrumentales, o el de la épica, que aparece como un modelo negativo.

además de mantener la brevedad en el Compendio Historial, se debe a que Jufré de Águila tenía "por cordura muy grande el no desestimar los avisos que a veces por impensados medios nos envía la Divina Providencia" (38). Así, aduce que la coz de un caballo que le quebró la pierna habría sido la razón por la que no pudo acompañar al gobernador al frente, salvándose de morir: "Me dio la vida Dios por un desastre / Que yo como ignorante sentí mucho / (...) Porque a subir con él, también muriera / Como murieron bravos capitanes" (1897: 107). El propio Jufré de Águila afirma que escribió la Astrología Judiciaria con el propósito de acallar a quienes lo llamaban "adivino" o "que con el diablo hablaba" debido a algunos pronósticos que habría hecho y que se habrían cumplido cabalmente (226). Se trataría de un gesto bastante arriesgado si consideramos que el Tribunal del Santo Oficio de la Inquisición de Lima emitió un "Edicto contra astrólogos, judiciarios y hechiceros" en 1629, es decir, apenas un año antes de la publicación del Compendio Historial en Lima. En este edicto quedaba "proveido y mandado [el] estudio de la astrologia judiciaria" y se condenaba a todos aquellos que "la exercitan con mezcla de muchas supersticiones, haciendo juicios por las estrellas y sus aspectos sobre los futuros contingentes, sucesos y casos fortuitos o acciones dependientes de la voluntad divina, o del libre alvedrio de los hombres" (cit. en Medina 1887: 36). La cercanía entre ambas publicaciones mueve a pensar que Jufré de Águila conoció el edicto y trató de hacer una defensa, dentro de la ortodoxia católica, de la ciencia de la adivinación por medio de los astros. 
El precepto horaciano de mezclar lo útil con lo dulce se replica en el calificativo de "provechosa y de gran gusto" con que Provecto caracteriza su historia desde los primeros versos (47). Esto remite nuevamente al Coloquio sentencioso de provecho y gusto que menciona Jufré de Águila y del que el Compendio Historial formaría parte. El autor parece haber seguido con atención aquí la traducción de los preceptos latinos que circularon profusamente en el Renacimiento español gracias a obras como el Arte Poética (1606) de Juan Díaz Rengifo, quien estipulaba que la "fama" poética podría lograrse perfectamente "pintando de vivo las cosas de la república" (5). Que el poema haya sido concebido en versos endecasílabos de estrofa indefinida y sin rima, mucho más prosaicos que las octavas reales con que está compuesta $L a$ Araucana, anticipa la distancia del Compendio Historial con la épica áurea. El mismo Rengifo aseguraba que, a diferencia de los versos escritos en octavas o tercetos, en los que "se celebran las hazañas de los Varones ilustres", los endecasílabos eran "mas libres para decir qualquier cosa", pues estos "versos sueltos...semejantes a los heroycos latinos...no piden alguna consonancia, ó correspondencia en los fines, sino total disonancia", ni tampoco reclaman "número de versos", permitiendo intercalar "dichos, sentencias y proverbios [que] queden fijos en la memoria" (84; bastardillas mías). Esto último puede verse claramente, a lo largo del poema, en la constante citación de autores clásicos con el fin de entregar lecciones sobre buen gobierno a las autoridades que leerán el texto. Tal registro remite al contexto discursivo de los sermones, que vinculan una historia y una lección, así como al de los loci communes, que vinculan dichos de los filósofos y colecciones de refranes y proverbios, este último un género que se hizo popular en España en el siglo XVI.

Pese a la influencia de la poética latina, Jufré de Águila declaraba en el prólogo que había adaptado su libro "al gusto que a lo moderno tienen hoy los hombres" (9). Aunque no se explicita el significado de este 'gusto moderno', podemos deducirlo de los sonetos encomiásticos que abren el libro gracias a los giros barrocos que se manifiestan en ellos. En el primero de los sonetos, dedicado por Rodrigo de Carvajal y Robles al Conde de Chinchón en "recomendación del autor y su libro", se pide al virrey:

Al Águila atended que en la frontera

De Arauco hizo tal presa en el bullicio

De Marte, que exaltó con su ejercicio

La sangre de Jufré a la quinta esfera (15). 
La quinta esfera es el coraje que hubo demostrado Melchor Jufré de Águila en el campo de Marte: la Guerra de Arauco. El apellido del autor permite alegorizar la virtud en el vuelo del águila con la virtud en la poesía, lo que aparece reforzado en la figura mítica de Hipocrene, fuente cuya agua produce la inspiración poética: "De Hipocrene verás tus nuevas alas / de fama trompas i del cielo escalas" (16). El águila conquista así doblemente el coraje y la inspiración, los elementos imprescindibles de toda epopeya, para dar inicio al poema.

El segundo soneto pertenece a Juan de Ailló (o Ayllón), fraile franciscano que, de acuerdo con José Toribio Medina, fue introductor del gongorismo en el continente americano (Biblioteca 363$)^{7}$. El fraile repite la alegoría del vuelo que representa el gesto etéreo del poeta, reforzado por la presencia del águila en el apellido del autor:

Contra el cisne veloz, tiempo labente[fugaz]

Águila a su pesar, si eterna, nueva.

Vuela hasta el Conde, sol de indiano cielo,

Que firme mirarás su luz pujante... (17).

Como ha explicado Rodrigo Cacho Casal (2013), la alegoría del vuelo en la poesía parnasiana representa el movimiento ascendente del poeta tanto en lo literario como en lo social. Se trata de un gesto doble que hace subir al poeta "desde la periferia de la poesía hasta su centro más alto" (1). El águila sube no solo a la cima de la poesía, sino también a la del poder y desde esa profanidad intenta articular su canto. Este gesto está en el origen de Las Soledades (1613) de Góngora, en el que el joven náufrago aparece, al momento de comenzar el poema, como individuo caído, arrojado al mundo. La referencia al Conde de Chinchón, a quien tanto Jufré de Águila como los demás autores de los sonetos dedican y recomiendan el libro, ilustra precisamente este tropo literario a la vez que político. Así, el soneto de este fraile y su presencia en la sección preliminar viene a ser un nexo clave en la mixtura de modelos e ideas que influyeron en el pensamiento poético de Jufré de Águila al momento de la concepción del Compendio Historial, que hace

\footnotetext{
Juan María Gutiérrez, que dedicó en 1865 quizás la única semblanza realizada hasta el momento sobre este fraile nacido en Lima en 1605, describe los poemas de Juan de Ayllón como una "imitación desgraciada de los extravíos de la escuela de Góngora y de sus cómplices, que comenzaba a penetrar en América” (2).
} 
sutiles guiños al barroco como alternativa a la poética que había dominado gran parte del siglo anterior y de la cual Ercilla era el gran referente.

Si bien es cierto que, hacia principios del XVII, La Araucana se había consolidado como modelo para muchas obras historiográficas y poéticas de la época, especialmente en el Reino de Chile, muchos letrados avecindados en los territorios coloniales comenzaban a mirar esta obra con cierto escepticismo. Las principales críticas convenían en que el poema de Ercilla, conocido por su engrandecimiento del guerrero mapuche, se mostraba demasiado susceptible a la ficción poética y menospreciaba la importancia de los primeros conquistadores. Su reconocimiento a la dignidad indígena, además, concedía tácito apoyo a la doctrina lascasiana. La imagen que se tenía de Ercilla, por otro lado, era la de un poeta muy cercano a la corte, mientras que muchos cronistas y poetas de la siguiente generación se sentían alejados de ella y denunciaban la centralización del poder colonial. Aunque es evidente que en La Araucana no se cuestiona el proyecto imperial como tal, sí se desliza un intento de reforma en la manera en que se llevaba a cabo la expansión de la Corona española, lo que provocó suspicacias entre quienes materializaban la conquista día a día, más aún entre encomenderos que, como Jufré de Águila, se sentían al margen de los virreinatos.

En este punto considero que el caso de Juan de Castellanos en Nueva Granada entrega valiosas pistas para entender el de Jufré de Águila. Como bien ha demostrado Emiro Martínez-Osorio (2016), la Elegías de varones ilustres de Indias (1589) se articuló como una propuesta textual alternativa a La Araucana, develando con ello algunos de los problemas centrales de la poética de la historia hacia fines del siglo XVI. Cabe agregar de igual forma que algunas de las críticas que se han realizado a Castellanos por haber concebido su obra como poema y no como crónica, explican en parte el que Jufré de Águila haya tomado la misma decisión. Por ejemplo, Menéndez Pelayo se quejaba de que Castellanos, "mal aconsejado por amigos que habían leído $L a$ Araucana", hubiera escrito su relación histórica en verso y no en prosa, como era la norma, de forma que "en vez de un montón de versos casi ilegibles de seguido, hubiéramos tenido una de las mejores y más caudalosas crónicas de la conquista" (cit. en Martínez-Osorio 19). Martínez-Osorio apunta a razones de otro orden para explicar la elección formal de estos poetas: "[the] authors could navigate sensitive topics and even avoid the constraints of official censorship by switching from historiography (...) to epic and heroic poetry, a genre that enjoyed great demand in the sixteenth century and could more 
easily be the beneficiary of royal endorsement" $(21)^{8}$. La poesía era, por tanto, ejemplar también en este sentido estratégico, pues permitía el acceso al debate público en torno a la política imperial de manera distinta a como lo hacían las obras historiográficas o etnográficas, que estaban mucho más expuestas a la censura o no podían articular fácilmente un modelo de autoridad. Tanto esta coyuntura, como la prosapia de La Araucana en el canon literario de la época, explican que Jufré de Águila eligiera el verso por sobre la prosa para articular su crítica hacia la guerra defensiva, aprovechando los surcos de un camino ya abierto, aunque luego tomara otra dirección.

En una línea similar a la de Juan de Castellanos, la emulación que realiza Jufré de Águila al poema de Ercilla presenta dos mecanismos fundamentales. El primero, el establecimiento de mayor autoridad para la escritura del poema, apelando tanto al referente ocular como al referente clásico para ofrecer una visión verdadera del proceso de conquista que, además, sea provechosa para el lector. El segundo, la inclusión de comentarios acerca de obras contemporáneas, precisamente de La Araucana, con el objetivo de articular una voz personal. De esta forma, la primera distinción que introduce Jufré de Águila respecto al texto de Ercilla tiene que ver con su permanencia en territorio americano, pues aunque ambos son poetas y soldados que escriben sobre lo que han visto, el hecho de que Jufré de Águila sea "cuarenta años testigo" (109) lo coloca en una mejor posición para juzgar la situación que se vive al interior del reino. Muchos han podido contar la historia de la conquista, pero pocos han podido hacerlo de manera integral,

Menos los coronistas ni escritores

(Digo los de estas partes) que en las Indias

Todas, hay muchos hombres que cansados

Y envejecidos en aquella guerra,

Cuentan della discursos diferentes,

Mas sin saber ninguno el cuento todo. (47)

Este "cuento todo", que se transforma en el gran horizonte del Compendio Historial, implica acotar el relato de la conquista provisto equívocamente por

\footnotetext{
"[los] autores podían tratar tópicos sensibles e incluso evitar las restricciones impuestas por la censura oficial pasando de la historiografía a la poesía épica y heroica, un género que gozaba de gran demanda en el s. XVI y podía ser más fácilmente beneficiario del apoyo real" (traducción mía).
} 
el discurso de la epopeya mediante una narrativa clara y precisa, preocupada más por los hechos que por los artificios retóricos. Sobre esta base se formula la crítica tanto al poema de Ercilla como a la política defensiva de la corona, elementos que Jufré de Águila ve íntimamente conectados:
(...) cual cuenta en su Araucana
El famoso de Arcila, aunque con muchas
Diferencias que yo enmendar pudiera
Si llevara esta historia por extenso (81).

Pero si sumariar los sucesos impide describirlos en profundidad, lo mismo permite al autor establecer su relato sin necesidad de enfrascarse en discusiones que, incluso en la época, podían parecer bizantinas. Esta preferencia por la brevedad antes que por la profundidad, a mi parecer, refuerza el carácter práctico con que fue concebida la obra, preocupada por informar sintética y ejemplarmente lo que otros han contado mediante figuras que distorsionaban una historia marcada por los triunfos del enemigo antes que por las glorias imperiales.

Dada la precaria situación de la empresa de conquista en el Reino de Chile hacia 1630, la epopeya no podía sostenerse como modelo de representación de la conquista. Se necesitaba con urgencia una nueva poética que pudiera ensalzar la guerra contra los nativos sin echar mano de los ideales caballarescos, para entonces evidentemente anacrónicos. Según John Beverley (1981), frente a una épica que "había perdido su vigor en el contexto de la decadencia imperial del siglo XVII”, el gongorismo fue el modelo poético que asumió el papel de recambio mediante "una estilización épica [de] materias no épicas, preservando valores inexistentes que legitimaban e idealizaban el proyecto histórico de una clase dominante" (40). De ahí que, situado frente a esta coyuntura, Jufré de Águila adoptara de la fórmula gongorista precisamente aquellos elementos más propicios para defender su posición como agente de la conquista. En vez de celebrar la grandeza inexistente de acciones vulgares, prefirió vulgarizar la 'epopeya' de Arauco y racionalizar el contenido de su poema:

tu autor siempre quiere

ponerte esta condición:

Si valiere tu razon,

vive i vuela; i si nó, muere (17). 
Como nos recuerda el mismo Beverley en un ensayo posterior, hacia el siglo XVII "la poesía [incluida la de Góngora] es todavía considerada como un discurso legislativo, coextensivo con el discurso de medios y fines de la razón de estado" (1988: 220). Así, consciente como estaba de la preponderancia que había adquirido el verso en el Reino de Chile, y de los beneficios que otorgaba para la construcción de un discurso crítico y legitimador al mismo tiempo, Jufré de Águila decidió articular su crónica como poema de sentido práctico en el que se defiende el proyecto de la conquista sin echar mano de guerreros míticos o alegorías parnasianas. El vuelo poético del Compendio Historial se trataba en realidad de un vuelo a ras de suelo, más pragmático que heroico, pero inscrito a su manera en las nuevas tendencias literarias que circulaban por las periferias de un imperio que, enfrentado a su propia finitud, necesitaba seguir justificando su expansión.

\section{POEMA Y POLÉMICA}

El Compendio Historial es, además de una crónica de la conquista de Chile, una crítica de la guerra defensiva implementada hacia principios del XVII en la Guerra de Arauco. Los versos de Jufré de Águila, escritos al calor de esos años, tuvieron por principal propósito revertir esta estrategia adoptada por la Corona a principios del s. XVII. Ya desde la dedicatoria al Virrey del Perú que inaugura el volumen, Jufré de Águila insiste en que "siendo tan fácil el conseguir la paz de aquella guerra envejecida por curso de casi noventa años (...) hoy son precisamente forzosos los dos mil infantes con que S.M. la tiene mandado seguir desde el año de 1606” (12). En la carta de Merlo de la Fuente, este atribuye su éxito en Arauco al haber seguido el modelo romano en la guerra de Cartago, es decir, "procediendo en la tala general que iba haciendo de todas comidas y legumbres, y en la quema de las casas y rancherías de aquellos purenes enemigos (...)" (31). Esta sería la única forma de triunfar sobre "aquellos enemigos más afamados de aquella guerra y dentro de su misma indómita provincia de Puren" (35). El propio Jufré de Águila describe el gobierno provisorio de Merlo de la Fuente entre 1610 y 1611 como un momento ejemplar de la empresa de conquista, afirmando que este 
Fue único entre los gobernadores

Que campeó cuatro meses de contino,

Sin cesar día ninguno de hacer guerra,

Y la hizo muy cruel a aquellos indios (131).

La controversia sobre el tipo de estrategia militar apropiada para la Guerra de Arauco debe analizarse, desde mi punto de vista, en correspondencia con la polémica (del gr. $\pi$ ó $\lambda \varepsilon \mu \rho \varsigma$, guerra) sobre la legitimidad de la guerra de conquista que se dio en la corte española desde las primeras décadas del siglo XVI. Este debate hizo posible, con las Leyes de Burgos pero sobre todo con las Leyes Nuevas de 1542, que la esclavitud indígena quedara tempranamente prohibida y se emprendieran diversas políticas de buen trato hacia los indios americanos que, por desgracia, no pudieron contrarrestar el régimen de violencia que se había impuesto. La institución de la encomienda, sistema de vasallaje que en la práctica funcionaba como un mecanismo de esclavitud, dio pie en 1550 a la controversia de Valladolid. Como afirma Mercedes Serna (2012), esta controversia protagonizada por Bartolomé de las Casas y Ginés de Sepúlveda en torno a la legitimidad de la encomienda y el estatuto político y moral de los indígenas, aunque no ponía en duda el proyecto imperial, provocó reformas importantes en la administración colonial (335). Algunas de las leyes de buen trato que se implementaron en el Reino de Chile a propósito de estas reformas están contenidas, además de otras ordenanzas, en la tasa de Gamboa de 1580. Este conjunto de leyes permitía a los indios, al menos en el papel, vivir en paz y con autonomía sobre ciertos territorios, pagando tributo a la corona de manera directa y no por medio de los españoles. Esos últimos, aún más, debían tener "cuidado de mirar por los dichos indios y encaminarlos en vida política y que vivan como hombres que estén en paz y que siembren para sí y para su tributo" (cit. en Silva Vargas 89).

De acuerdo con Williams Mejías (1992), la doctrina de Las Casas sobre la igualdad entre colonizados y colonizadores se había difundido en Chile gracias a la presencia del fraile dominico Gil González de San Nicolás, quien había sido discípulo en Salamanca del también defensor de la causa indígena Francisco de Victoria (53). Fray González no solo polemizó con quienes abogaban por una estrategia ofensiva en la Guerra de Arauco, sino que llegó a justificar la sublevación indígena a causa de los terribles abusos cometidos por los soldados españoles. De hecho, el referente de la Guerra Justa que subyace a La Araucana podría ser producto de la influencia que 
ejerció fray González en Ercilla, el cual pudo haber escuchado sus sermones cuando coincidieron en Santiago. Es probable, empero, que el autor de $L a$ Araucana se hiciera sensible a la causa indígena cuando trabajaba como paje en el Palacio de Felipe II, a pocos pasos del convento de San Gregorio en Valladolid, en el que residía Las Casas y se dejaban oír muchas de las disquisiciones teológicas que decantaron en la promulgación de las Leyes Nuevas.

Al principio del siglo XVII, las ideas lascasianas fueron retomadas en Chile por el jesuita Luis de Valdivia para justificar una estrategia defensiva en la Guerra de Arauco. Este misionero no solo había aprendido la lengua mapuche, publicando un Arte y gramatica general de la lengua que corre en todo el Reyno de Chile: con un vocabulario, y confessionario (1606), sino que además intervino directamente en materia de gobierno para frenar las invasiones en territorio indígena. Jufré de Águila, a diferencia de Ercilla, no se dejó influenciar por estas ideas reformistas y prefirió abogar por una política ofensiva, especialmente luego del establecimiento de una frontera con el territorio mapuche en 1612 (ver las ordenanzas del Virrey Montesclaros en las Provisiones y Cartas del rey Felipe III). Esta frontera, considerada por muchos un reconocimiento tácito a la autonomía indígena, fue muy apreciada por los misioneros, pues les permitía evangelizar en los mismos territorios indígenas en un contexto de libertad y no de sometimiento. En su Compendio Historial, sin embargo, Jufré de Águila asegura que

Este orden bueno, viendo era dañoso,

A los indios por ser muy incapaces,

Y gente sin razón, muy holgazana,

Que los perdía en vez de aprovecharlos

Ni correspondieron, ni otra cosa

Hicieron, mas que de a guerra apercibirse (110).

Jufré de Águila culpaba a los misioneros de la situación en que se encontraba la conquista del Reino de Chile, pues habían convencido a la corona de "que los agravios / Que antiguamente algunos [indios] recibieron, / Habían sido la causa de la guerra" (138). Asimismo, criticaba su incapacidad en asuntos militares. Por ejemplo, durante una campaña en territorio mapuche, unos soldados consultaron con misioneros cómo entrar en diálogo con los indios, a lo que respondieron que "sin talar las comidas, mensajeros / Les enviase a la paz los convidando" (94). No obstante, los guerreros mapuche 
...no dieron

La prometida paz, ni más tornaron

Con alguna respuesta mala o buena

Antes de la Imperial en el camino

Dos soldados y un clérigo mataron (95).

En los versos 139-140 del Compendio Historial se consigna igualmente el caso de tres "inocentes padres" asesinados por caciques hacia 1615 que el gobierno colonial utilizó para demostrar la naturaleza maliciosa de los indios y la necesidad de someterlos. Hay evidencia, además, de que Jufré de Águila criticó abiertamente las regulaciones impuestas por la Corona entre sus períodos ediles de 1612 y 1618, tanto así que el padre Luis de Valdivia se quejó con el rey en un carta diciendo que "un caballero de Santiago nombrado Melchor Jufré de Águila lo contradecía siendo procurador de la ciudad" (Medina, Biblioteca 357). Esta misma queja se repite, aunque sin mencionar a Jufré de Águila, en una carta de 1615:

Cada día veo más claramente el acierto que tuvo la resolución de poner Raya a esta guerra, y que sólo sea defensiva [pues] no entrándole a ofender [al enemigo] se ha de ir experimentando la quietud [aunque] bien sé que se hacen informaciones y se piden cartas a cabildos pidiendo se torne a la guerra ofensiva, y no tiene más motivos que haber habido algunos ladrones, que viene a hurtar, o tropillas de salteadores, los cuales siempre han quedado en los fines de las guerras por algunos años (Luis de Valdivia, Carta ... 1615; bastardillas mías).

Estos alegatos en contra de la guerra defensiva no tenían por objeto último la invalidación de un argumento teológico ya consolidado entre los misioneros (la existencia del alma entre los indígenas), sino que continuar el sistema de esclavitud indígena en el que se sustentaba la economía colonial. Prueba de la dureza con que el cuerpo de conquistadores argumentó contra la estrategia defensiva, de forma incluso más radical que el Compendio Historial, es el panfleto intitulado Tratado de la importancia y utilidad que ay en dar por esclavos a los indios rebelados de Chile, firmado por Melchor Calderón en 1607, en el que no solo se defiende una guerra ofensiva sino que se cuestiona una premisa harto tiempo instalada en la política de conquista, como era la ilegalidad de la esclavitud indígena. En definitiva, aquellos encomenderos que, como Jufré de Águila, tenían el poder de la letra, se organizaron discursivamente para que las condiciones creadas por las Leyes 
Nuevas y las ideas lascasianas fracasaran en el Reino de Chile, provocando un clima de violencia que hizo posible el retorno de una estrategia ofensiva y se promulgaran las leyes de perpetuación de la encomienda, institución que se prolongaría en el territorio nacional, a diferencia de otras regiones de América, hasta bien entrado el s. XVIII.

\section{CONCLUSIONES}

El Compendio Historial se escribió con el propósito de defender la política de expansión colonial y justificar la guerra contra el pueblo mapuche en un periodo en que este había logrado interponer una barrera a la colonización española y la corona, influenciada por la Iglesia, iniciaba relaciones diplomáticas para establecer la paz. El proyecto fue originalmente concebido por Jufré de Águila como una crónica en prosa que tuviera la aprobación oficial del Consejo del Rey, pero ante la indiferencia de la corte decidió publicar su relato de modo independiente y como diálogo poético. Esta decisión es de la máxima importancia, pues revela que ciertas prácticas escriturales y editoriales estaban asociadas a una conciencia sobre la forma como medio de expresión y viceversa. Además de los beneficios que otorgaba el verso ante los aparatos de censura para articular su crítica a la política defensiva de la Corona, las razones de la elección hecha por Jufré de Águila pueden encontrarse en el conflictivo antecedente literario que representó La Araucana para los letrados de principios del siglo XVII. Aunque criticada por sus cuestionamientos a la empresa de conquista, esta obra había alcanzado un lugar central en el canon literario de la época y no pocos historiadores se vieron impulsados a escribir sus relaciones históricas siguiendo el modelo de la epopeya. Jufré de Águila, haciendo eco de este modelo al articular su crónica en verso, intentó al mismo tiempo tomar distancia de él siguiendo ideas poéticas provenientes tanto de la antigüedad latina como de las nuevas corrientes literarias divulgadas por el territorio americano. Como resultado, el Compendio historial presenta elementos de la poética horaciana y giros barrocos que, sumados al modelo historiográfico de las crónicas abreviadas de la tradición humanista, lo sitúan a medias entre la historia y la poesía sin que podamos definir con certeza su género discursivo.

Como bien ha explicado María José Vega (2010), la poesía del Siglo de Oro tuvo en muchos casos una función bastante concreta de propaganda política del imperio, lo que se expresó en autores menos preocupados de 
cuestiones estéticas que de consolidar el dominio colonial. Así, podemos imaginar a Jufré de Águila sintiéndose más cercano a una tradición de "historiadores, reparadores de la ignorancia o de una injusticia arraigada, notarios fidedignos del presente" (108) que a una tradición de poetas de orientación petrarquista. Simultáneamente, como sostiene Mercedes Blanco (2013), esto no impidió que historiadores y soldados echaran mano del uso libre del verso, puesto que los poemas épicos enseñaban al fin y al cabo lo mismo que "los autores de tratados y diálogos sobre el arte de la guerra y la milicia: la formación y las virtudes del soldado, del artillero, del capitán" (16). En consecuencia, el concepto de poema que se presenta en el Compendio Historial está fuertemente impregnado de los modos didácticos del discurso de la historia, que en el siglo XVII podían confundirse sin problemas con el acto de deleitar, enseñar y persuadir por medio del verso. De hecho, el que Jufré de Águila haya unido textos en verso y otros en prosa en un mismo libro y quisiera difundirlo de esta forma indica que historia y poesía no eran consideradas elementos realmente excluyentes entre sí.

Si bien el valor que en la actualidad se le ha dado a esta obra no pasa de ser meramente documental, hay que considerar que textos como este circularon profusamente en los territorios coloniales, constituyendo otro campo de batalla entre quienes intentaban hacerse un lugar en el proyecto de expansión de la Corona española. De acuerdo con Rolena Adorno (1987), la lucha por el poder de la letra en la ciudad colonial no solo se expresó a nivel de las ideas, sino que "en las pugnas por la impresión y supresión de libros" (4). Es decir, en la lucha por la legitimidad del discurso en tanto realidad material. El propio Jufré de Águila anotaba en el prólogo a su Compendio Historial que por haber "ganado por la mano a todos los que quisieren tomar este camino", muchos "procurarán que éste mi libro muera sin aplauso" (10). Así, para este autor se había vuelto evidente que la función de la escritura no consistía solo en legitimar al imperio, sino que también al escritor mismo en su calidad de agente del poder letrado en el medio local. La fluidez con que se propagó el discurso imperial en las periferias solo pudo ser posible, como nos lo recuerda Ángel Rama, gracias al papel que jugaron los intelectuales y, en particular, los poetas en la consolidación de la ciudad letrada, quienes contribuyeron desde la poesía a la articulación de un orden autónomo, abstracto y racionalizador que los ubicó al centro del poder real de la sociedad (Rama 1998: 35-40). Que el libro no haya trascendido como texto literario debe atribuirse a un conjunto de condiciones entre las que, además del escaso valor literario del libro o de una caza de brujas jesuita, no podemos descartar el azar. Lo cierto 
es que este tipo de articulaciones poéticas -fallidas, heterodoxas pero también coherentes con las transformaciones experimentadas por la modernidad emergente- fueron claves para dar forma al orden letrado colonial.

\section{BIBLIOGRAFÍA}

Adorno, Rolena. "La 'Ciudad letrada' y los discursos coloniales”. Hispamérica 16, 48 (1987): 3-24.

Beverley, John. "Nuevas vacilaciones sobre el barroco". Revista de Crítica Literaria Latinoamericana 14, 28 (1988): 215-227.

“Sobre Góngora y el gongorismo colonial”. Revista Iberoamericana XLVII (1981): 114-115.

Blanco, Mercedes. "La épica áurea como poesía". Los géneros poéticos del siglo de oro. Eds. Rodrigo Cacho Casal y Anne Holloway. Tamesis: Boydell y Brewer, 2013. 13-30.

Cacho Casal, Rodrigo. "Introducción: Géneros, centros, periferias". Los géneros poéticos del siglo de oro. Eds. Rodrigo Cacho Casal y Anne Holloway. Tamesis: Boydell y Brewer, 2013.

Calderón, Melchor. Tratado de la importancia y utilidad que ay en dar por esclavos a los indios rebelados de Chile: dispútase en él, si es lícito o no el darlos por esclavos y ponerle razones por ambas partes.... Chile: Biblioteca Nacional de Chile, original de 1607. Web.

Chartier, Roger. L'ordre des livres. Lecteurs, auteurs, bibliothèques en Europe entre XIV et XVIII ${ }^{e}$ siècle. Aix-en-Provence: Alinea, 1992.

The Author's Hand and the Printer's Mind. Cambridge: Polity Press, 2014.

Covarrubias, Sebastián de. Tesoro de la lengua castellana, o española. Madrid: Luis Sánchez, 1611.

Ercilla, Alonso de. La Araucana. Edición de Isaías Lerner. Madrid: Cátedra, 1993.

Espitia, Leonardo. "Brevitas, amplificatio: dos recursos retoricos utilizados por Hernán Pérez de Oliva en su Historia de la Conquista de la Nueva España”. Perifrasis 5, 10 (2014): 96-113.

Foucault, Michel. El orden del discurso. Alberto González Troyano, trad. Barcelona: Gedisa, 2005 [1970].

Gayangos, Pascual de y Enrique Vedia. "Adiciones y notas de los traductores". En George Ticknor, Historia de la literatura española. Madrid: Imprenta y Estereotipía de M. Rivadeneira, 1854. Tomo III, pp. 453-562.

Gutiérrez, Juan María. Estudios biográficos y críticos sobre algunos poetas sud-americanos anteriores al siglo XIX. Buenos Aires: Imprenta del Siglo, 1865.

Jufré de Águila, Melchor. Compendio Historial del Descubrimiento i Conquista del Reino de Chile, seguido de dos discursos: Avisos prudenciales de gobierno i guerra, De la Astrolojía Judiciaria. Advertencia de Luis Montt. Prólogo de Diego Barrios Arana. Santiago: Universidad de Chile, 1897[1630]. Ver http://www.historia.uchile.cl 
Compendio Historial del descubrimiento, Conquista, y Guerra del Reyno de Chile, con otros dos discursos. Uno de Avisos prudenciales en las materias de gobierno y guerra. Y otro de lo q'católicamente, se deve sentir de la Astrologia Judiciaria. Lima: Francisco Gomez Pastrana, 1630. Ver https://repository.library.brown.edu/studio/item/bdr:13282/

Quesada Gómez, Catalina. “Gonzalo Jiménez de Quesada: la retórica frente al infortunio”. Herencia cultural de España en América. Actas del I Encuentro de Literatura Hispanoamericana Colonial. Trinidad Barrera, coord. Sevilla: Universidad de Sevilla, 2007.

Martínez-Osorio, Emiro. Authority, Piracy, and Captivity in Colonial Spanish American Writing. Juan de Castellanos's Elegies of Illustrious Men of the Indies. Lanham: Bucknell U P, 2016.

Medina, José Toribio. Biblioteca hispano-chilena (1523-1817). Google Books [1897].

Historia del Tribunal del Santo Oficio de la Inquisición de Lima. 1569-1820. Tomo II. Santiago: Imprenta Gutenberg, 1887.

Mejías, William. Las ideas de la guerra justa en Ercilla y La Araucana. Santiago de Chile: Universitaria, 1992.

Montesclaros, Marqués de. Provisiones y cartas del Rey Felipe III, nuestro señor y del excelentísimo Marqués de Montes Claros, Virrey del Perú con otros sus órdenes y decretos sobre la nueva forma que le da en la guerra y buen asiento en el Reyno de Chile. Con licencia del dicho Señor Virrey. Lima: Francisco del Canto, 1612. Web.

Muñoz Correa, Juan Guillermo. "La concesión de mercedes de tierra en la doctrina de Malloa (Colchagua, Siglos XVI y XVII)”. Espacio Regional 1, 5 (2008): 69-95.

"Viñas en la traza de Santiago del Nuevo Extremo y chacras colindantes (Siglos XVI-XVII)”. Revista de Historia Social y de las Mentalidades X, 1 (2006): 121-177.

Rama, Ángel. La ciudad letrada. Prólogo de Hugo Achugar. Montevideo: Arca, 1998.

Rengifo, Juan Díaz. Arte poética española. Ed. Antonio Martí Alanís. Madrid: Servicio de Publicaciones del Ministerio de Educación y Ciencias, 1977[1606].

Serna, Mercedes. "Las Leyes Nuevas". La conquista del Nuevo Mundo. Textos y documentos de la aventura americana. Buenos Aires-Barcelona: Castalia, 2012. Pp. 335-362.

Silva Vargas, Fernando. "La tasa de Gamboa". Tierras y pueblos de indios en el Reino de Chile: esquema histórico-jurídico. Santiago: Universidad Católica de Chile, Estudios de Historia del Derecho Chileno No 7, 1962. 85-92.

Téllez, Jorge. Poéticas del Nuevo Mundo. Articulación del pensamiento poético en América Colonial: siglos XVI, XVII y XVIII. México: Siglo XXI - Universidad Autónoma de Sinaloa - Colegio de Sinaloa, 2012.

Valdivia, Luis de, SJ. Carta de 1615 septiembre 7 Concepción a Su Magestad [manuscrito]. Web.

Vega, María José. “Idea de la épica en la España del Quinientos”. La teoría de la épica en el siglo XVI. Eds. María José Vega y Lara Vilà. Vigo: Academia del Hispanismo, 2010. 108-135. 